\title{
Effects of Postresuscitation $N$-Acetylcysteine on Cerebral Free Radical Production and Perfusion During Reoxygenation of Hypoxic Newborn Piglets
}

\author{
TZE-FUN LEE, CORINNE N. TYMAFICHUK, DAVID L. BIGAM, AND PO-YIN CHEUNG \\ Department of Pediatrics [T.-F.L., C.N.T., P.-Y.C.], Department of Surgery [D.L.B.], University of Alberta, Edmonton, Alberta, \\ Canada T6G 2E1
}

\begin{abstract}
Hydrogen peroxide $\left(\mathrm{H}_{2} \mathrm{O}_{2}\right)$ and nitric oxide (NO) contribute to the pathogenesis of cerebral hypoxic-ischemic injury. We evaluated the neuroprotective effect of $N$-acetyl-L-cysteine (NAC, a free radical scavenger) against oxidative stress and perfusion in a model of neonatal hypoxia-reoxygenation (H-R). Piglets (1-3 d, 1.6-2.3 kg) were randomized into a sham-operated group (without H-R) $(n=5)$ and two H-R experimental groups $(2 \mathrm{~h}$ normocapnic alveolar hypoxia followed by $4 \mathrm{~h}$ reoxygenation) $(n=$ 7/group). Five minutes after reoxygenation, piglets were given either i.v. saline (H-R controls) or NAC (30 mg/kg bolus then $20 \mathrm{mg} / \mathrm{kg} / \mathrm{h}$ infusion) in a blinded-randomized fashion. Heart rate, mean arterial pressure, carotid arterial blood flow (transit-time ultrasonic probe), cerebral cortical $\mathrm{H}_{2} \mathrm{O}_{2}$ and $\mathrm{NO}$ production (electrochemical sensor), cerebral tissue glutathione and nitrotyrosine levels (enzyme-linked immunosorbent assay) were examined. Hypoxic piglets were acidotic ( $\mathrm{pH}$ 6.88-6.90), which recovered similarly in the H-R groups $(p>$ 0.05 versus shams). Postresuscitation NAC treatment significantly attenuated the increase in cortical $\mathrm{H}_{2} \mathrm{O}_{2}$, but not $\mathrm{NO}$, concentration during reoxygenation, with lower cerebral oxidized glutathione levels. NAC-treated piglets had significantly higher carotid oxygen delivery and lower cerebral lactate levels than that of H-R controls with corresponding changes in carotid arterial flow and vascular resistance. In newborn piglets with $\mathrm{H}-\mathrm{R}$, postresuscitation administration of NAC reduced cerebral oxidative stress and improved cerebral perfusion. (Pediatr Res 64: 256-261, 2008)
\end{abstract}

$\mathrm{N}$ eonatal asphyxia followed by reperfusion is one of the major causes of permanent brain injury in neonatal care. Although the exact mechanisms have not been fully elucidated, there is growing evidence that reactive oxygen species (ROS) are important for the reperfusion injury after asphyxia (1). Excess production of ROS such as superoxide anion, hydroxyl radical, hydrogen peroxide $\left(\mathrm{H}_{2} \mathrm{O}_{2}\right)$, and nitric oxide (NO) has been reported during ischemia-reperfusion (I-R) or hypoxia-reoxygenation (H-R). Some of these radicals and their metabolites cause cellular damage and apoptotic cell death by oxidizing proteins, inducing lipid peroxidation and damaging deoxyribonucleic acid. $N$-Acetyl-L-cysteine (NAC), a precursor of glutathione and a potent thiol-containing anti-

Received January 25, 2008; accepted April 8, 2008.

Correspondence: Po-Yin Cheung, MBBS, Ph.D., F.R.C.P., NICU Royal Alexandra Hospital, 10240 Kingsway Avenue, Edmonton, Alberta, Canada T5H 3V9; e-mail: poyin@ualberta.ca

Supported by grants from the Canadian Institute of Health Research. PYC is an investigator of the Canadian Institutes of Health Research and the Alberta Heritage Foundation for Medical Research. oxidant, has been shown to have certain beneficial effects on neuronal protection after I-R or H-R (2,3). Administration of NAC has been shown to reduce cerebral injury in adult rats with I-R (2) and neonatal rats with lipopolysaccharidesensitized hypoxia-ischemia (3). We previously reported that postresuscitation treatment with $\mathrm{NAC}$ reduced cerebral $\mathrm{H}_{2} \mathrm{O}_{2}$ production as well as lipid peroxidation in moderately hypoxic newborn piglets after $2 \mathrm{~h}$ of reoxygenation (4).

Other than $\mathrm{H}_{2} \mathrm{O}_{2}$, there is substantial evidence supporting the involvement of $\mathrm{NO}$ in the pathogenesis of cerebral $\mathrm{H}-\mathrm{R}$ injury $(1,5)$. NO cytotoxicity may be secondary to NO itself causing persistent inhibition of mitochondrial respiration or NO reacting with superoxide anion to generate peroxynitrite, a potent oxidant. Because peroxynitrite can be detoxified by glutathione (GSH), NAC treatment may be beneficial by directly reducing peroxynitrite and by replenishing endogenous GSH source. However, controversial effects of NAC on NO production during I-R and H-R have been reported (2,6-8). Associated with reducing the cerebral injury, NAC has been shown to decrease plasma nitrite and nitrate (NOx, a biologic marker of NO production) levels and NO synthase expression in gerbils (6) and rats (2) after I-R, respectively. In contrast, an increase in NOx levels in the renal tissue (7) and the plasma (8) following I-R has been reported after NAC treatment. By using an electrochemical NO sensor, marked increase in cerebral NO has been reported in both newborn (9) and adult swine (10) during H-R and I-R. Therefore, it is of interest to examine whether NAC can elicit its beneficial effects by minimizing $\mathrm{NO}$ production.

Using an acutely instrumented swine model of neonatal H-R, the objective of the present study was to examine whether NAC can attenuate $\mathrm{NO}$ and $\mathrm{H}_{2} \mathrm{O}_{2}$ production after reoxygenation in the cerebral cortex after severe hypoxia. We also examined the effects of NAC on cerebral oxidative stress and perfusion by measuring the related biochemical markers, carotid blood flow $(\mathrm{CBF})$, and oxygen delivery during reoxygenation.

\section{METHODS}

All experiments were conducted in accordance with the guidelines and approval of the Health Sciences Animal Policy and Welfare Committee,

\footnotetext{
Abbreviations: CBF, Carotid blood flow; CVP, Central venous pressure; H-R, Hypoxia-reoxygenation; I-R, Ischemia-reperfusion; MAP, Mean arterial pressure; NAC, N-Acetylcysteine; ROS, Reactive oxygen species
} 
University of Alberta. Newborn Yorkshire-Landrace piglets $1-3 \mathrm{~d}$ of age weighing $1.6-2.3 \mathrm{~kg}$ were used.

Animal preparation. The animal preparation was similar to that described previously $(4,11)$. Briefly, anesthesia was initially maintained with inhaled isoflurane. After mechanical ventilation through tracheostomy was started, the animals were given i.v. fentanyl $(0.005-0.03 \mathrm{mg} / \mathrm{kg} / \mathrm{h})$, midazolam $(0.1-0.2$ $\mathrm{mg} / \mathrm{kg} / \mathrm{h}$ ), and pancuronium $(0.05-0.1 \mathrm{mg} / \mathrm{kg} / \mathrm{h}$ ) for analgesic, sedative, and muscle relaxation purposes, respectively. Inhalational anesthesia was then discontinued. These medications were chosen because of their common use in the clinical arena, although some may have controversial actions in newborn subjects. Oxygen saturation was continuously monitored with a pulse oximeter (Nellcor, Hayward, CA), and heart rate, and blood pressure were measured with a 78833B monitor (Hewlett Packard). Fractional inspired oxygen concentration $\left(\mathrm{F}_{\mathrm{i}} \mathrm{O}_{2}\right)$ was maintained at $0.21-0.24$ for oxygen saturations between 90 and $100 \%$. Maintenance fluids consisted of $5 \%$ dextrose at $10 \mathrm{~mL} / \mathrm{kg} / \mathrm{h}$ and Lactated Ringer's solution at $2 \mathrm{~mL} / \mathrm{kg} / \mathrm{h}$. The body temperature was maintained at $38.5-39.5^{\circ} \mathrm{C}$ using an overhead warmer and a heating pad.

Surgical procedure. Argyle catheters (5F; Sherwood Medical Co., St. Louis, MO) were inserted via the right femoral artery and vein for continuous measurement of mean arterial pressure (MAP, at abdominal aorta) and central venous pressure (CVP, at right atria), respectively. All medications and fluids were administered via the femoral venous catheter. Via a tracheotomy, pressure-controlled assisted ventilation was commenced (Model IV-100, Sechrist Industries Inc., Anaheim, CA) with pressure of $20 / 4 \mathrm{~cm} \mathrm{H}_{2} \mathrm{O}$ at a rate of 18-20 breaths/min. Meanwhile, an ultrasound flow probe (2RB, Transonic System Inc., Ithaca, NY) was encircled around the right common carotid artery and attached to a Transonic T206 blood flow meter for continuous measurement of CBF.

The piglet was then placed in the prone position with the head mounted in a stereotaxic holder. Using bregma as the reference point, two stainless steel guide cannulae (19 gauge) were implanted (at a depth of $6 \mathrm{~mm}$ ) in the right frontoparietal cortex using the following co-ordinates: antero-posterior $=6.5$ and $8 \mathrm{~mm}$; and lateral $=4 \mathrm{~mm}$ for $\mathrm{H}_{2} \mathrm{O}_{2}$ and $\mathrm{NO}$ sensors, respectively. The co-ordinates for the cerebral cortex were based atlas constructed with several pilot studies. This cerebral region was chosen because significant histologic and biochemical injury was observed in our previous study $(4,12,13)$. The piglet was replaced in the side position after cannulae implantation. All incisions were closed to minimize evaporative heat loss. After all surgical procedures were completed, pancuronium infusion was discontinued.

Experimental protocol. After surgical instrumentation, animals were stabilized for 45-60 min. Piglets were randomized into a sham-operated group (without $\mathrm{H}-\mathrm{R}$, ventilated with $\mathrm{F}_{\mathrm{i}} \mathrm{O}_{2}$ of 0.21 throughout the experimental period, $n=5$ ) or two H-R experimental groups ( $n=7$ each) with $2 \mathrm{~h}$ normocapnic alveolar hypoxia induced by decreasing the $\mathrm{F}_{\mathrm{i}} \mathrm{O}_{2}$ to $0.09-0.12$ using nitrogen and oxygen gas mixture. The $\mathrm{F}_{\mathrm{i}} \mathrm{O}_{2}$ was adjusted as tolerated by the piglets to obtain severe hypoxemia $\left(\mathrm{PaO}_{2}\right.$ of $\left.25-35 \mathrm{~mm} \mathrm{Hg}\right)$ for $2 \mathrm{~h}$. To maintain normocapnia, the ventilator rate was adjusted to $12-20$ breaths/min. After hypoxia, the piglets were resuscitated with a $\mathrm{F}_{\mathrm{i}} \mathrm{O}_{2}$ of 1.0 for $1 \mathrm{~h}$, followed by 0.21 for another $3 \mathrm{~h}$. This protocol of hypoxia and reoxygenation was close to but not equal to clinical practice $(4,11)$. Five minutes after reoxygenation, piglets received either normal saline (H-R control) or NAC ( $30 \mathrm{mg} / \mathrm{kg}$ bolus and $20 \mathrm{mg} / \mathrm{kg} / \mathrm{h}$, i.v.) in a randomized fashion. To maintain blinding, NAC and normal saline were freshly reconstituted in a standard volume by a technician not involved in the experiment and identified by number only. The drugs were clear, odorless, and covered. The drugs were given in a bolus of $3 \mathrm{~mL} / \mathrm{kg}$ and followed by $2 \mathrm{~mL} / \mathrm{kg} / \mathrm{h}$ infusion for $4 \mathrm{~h}$. This dose of NAC was chosen based on our previous experiments, which showed an effective reduction on cerebral cortical $\mathrm{H}_{2} \mathrm{O}_{2}$ concentration over $2 \mathrm{~h}$ of reoxygenation (4). At the end of the experiment, the piglet was euthanized with pentobarbital $(100 \mathrm{mg} / \mathrm{kg}$, i.v.). Brains were removed rapidly and flash frozen in isopentane at $-80^{\circ} \mathrm{C}$ for subsequent analysis.

Hemodynamic recordings. Hemodynamic parameters (heart rate, MAP, CVP, and CBF) were recorded at baseline $(0 \mathrm{~min})$, every 15 and $30 \mathrm{~min}$ during hypoxia and reoxygenation, respectively. CBF was indexed by dividing the flow by the animal's body weight. Carotid vascular resistance was calculated as (MAP - CVP)/CBF; whereas carotid oxygen delivery was calculated by arterial oxygen content $\times \mathrm{CBF}$.

Cerebral cortical hydrogen peroxide and NO measurement. The changes in cortical $\mathrm{H}_{2} \mathrm{O}_{2}$ and $\mathrm{NO}$ during $\mathrm{H}-\mathrm{R}$ were measured directly by electrochemical $\mathrm{H}_{2} \mathrm{O}_{2}$ and $\mathrm{NO}$ sensors (HPO-100 and NO-100, World Precision Instruments Ltd. Sarasota, FL). The $\mathrm{H}_{2} \mathrm{O}_{2}$ and $\mathrm{NO}$ sensors were inserted through the posterior and anterior guide cannula into the cortex area, respectively. The sensors were connected to a computer-controlled data acquisition system (Apollo 4000, World Precision Instruments Ltd.). The signal outputs were recorded continuously throughout the experiment. Immediately before and after each experiment, the $\mathrm{H}_{2} \mathrm{O}_{2}$ sensor was calibrated with $1 \mathrm{mM} \mathrm{H}_{2} \mathrm{O}_{2}$ in phosphate buffer (10 mM, pH 7.4), whereas the NO sensor was calibrated with
$0.09 \mathrm{mM} S$-nitroso- $N$-acetyl-penicillamine in $0.1 \mathrm{M}$ copper sulfate solution, according to manufacturer's instructions. The mean value was used for converting the signal outputs. The relative changes in cortical $\mathrm{H}_{2} \mathrm{O}_{2}$ and $\mathrm{NO}$, expressed in $\mu \mathrm{M}$ and $\mathrm{nM}$, respectively, were calculated with reference to the normoxic baseline after stabilization.

Determination of cortical glutathione, nitrotyrosine, and lactate. A block of cortical tissue $\left(5 \times 5 \times 5 \mathrm{~mm}^{3}\right)$ from the left side of the cortex corresponding to the cannulation area of the right side was dissected. The tissue was then homogenized with $5 \mu \mathrm{L} / \mathrm{mg}$ of $50 \mathrm{mM}$ phosphate buffer containing $1 \mathrm{mM}$ ethylenediaminetetraacetate $\left(\mathrm{pH} \mathrm{7.0)}\right.$ and stored at $-80^{\circ} \mathrm{C}$ until biochemical analyses. The cortical levels of GSH/GSSG and nitrotyrosine were measured using glutathione (\#703002, Cayman Chemical, Ann Arbor, MI) and nitrotyrosine assay kits (Hycult Biotechnology, the Netherlands), respectively. Brain lactate was assayed by enzyme-coupled NADH colorimetry method with spectrophotometry at $340 \mathrm{~nm}$. The protein content was determined by bicinchoninic acid assay kit (Sigma Chemical Co.).

Statistical analysis. All results are expressed as mean \pm standard error of the mean. Two-way repeated measures analysis of variance (ANOVA) and one-way ANOVA and Kruskal-Wallis (ANOVA on ranks) test were used to study the differences between groups for parametric and nonparametric, respectively, followed by post hoc testing with Fisher Least Significant Method and Dunn's test for pairwise comparisons with the H-R control group as appropriate. Correlation between variables was studied by Pearson Moment test. Statistical analyses were performed using SigmaStat (v.2.0, Jandel Scientific, San Rafael, CA). Significance was set at $p<0.05$.

\section{RESULTS}

Effects of NAC on various physiologic parameters. The piglets aged $2 \pm 0.3 \mathrm{~d}$ and weighed $1.9 \pm 0.1 \mathrm{~kg}$, with no significant differences among groups. As shown in Table 1, sham-operated piglets did not show significant differences in various physiologic parameters throughout the experimental period. After exposure to hypoxia for $2 \mathrm{~h}$, the arterial $\mathrm{pH}, \mathrm{Po}_{2}$, and $\mathrm{HCO}_{3}$ levels of piglets decreased significantly (versus sham-operated piglets, $p<0.05$ ) (Table 1 ). Upon reoxygenation, all these physiologic parameters recovered gradually toward the normoxic baseline values. There were no significant differences in arterial blood gas among the sham-operated and two H-R groups at the end of the experiment (Table 1). There was no significant difference in $\mathrm{PaCO}_{2}$ among groups throughout the experimental period.

Accompanied by the marked decrease in $\mathrm{pH}$, the MAP significantly decreased to $55 \%$ of the normoxic baseline value after $2 \mathrm{~h}$ of hypoxemia $(p<0.05)$ (Table 1$)$. After the immediate recovery upon reoxygenation, MAP deteriorated and remained lower than the normoxic baseline value throughout the reoxygenation period $(p<0.05)$ (Table 1). In contrast, the heart rate of the H-R control group tended to be higher than that of sham-operated piglets at the end of hypoxia and throughout the reoxygenation period (Table 1).

The temporal changes in various physiologic parameters during hypoxia and reoxygenation of NAC-treated piglets were not different from those observed in the H-R control group (Table 1).

Effects of NAC on cerebral cortical NO production. The NO concentration of two H-R groups decreased slightly at the end of hypoxemia ( $p>0.05$ versus normoxic baseline) (Fig. 1). Upon reoxygenation, the NO concentration of the H-R control group raised immediately with a maximum increase of $155 \pm 50$ $\mathrm{nM}$ at $90 \mathrm{~min}$ after reoxygenation. The temporal pattern of $\mathrm{NO}$ concentration of NAC-treated piglets during reoxygenation was similar to that of the H-R control group $(p>0.05)$ (Fig. 1).

Effects of NAC on cerebral cortical hydrogen peroxide production. Cortical $\mathrm{H}_{2} \mathrm{O}_{2}$ concentrations of $\mathrm{H}-\mathrm{R}$ control and 
Table 1. Arterial blood gas and hemodynamic variables during hypoxia and reoxygenation

\begin{tabular}{|c|c|c|c|c|c|c|}
\hline \multirow[b]{2}{*}{ Group } & \multirow[b]{2}{*}{ Baseline } & \multirow[b]{2}{*}{ End of hypoxia } & \multicolumn{4}{|c|}{ Reoxygenation } \\
\hline & & & $10 \mathrm{~min}$ & $60 \mathrm{~min}$ & $120 \mathrm{~min}$ & $240 \mathrm{~min}$ \\
\hline \multicolumn{7}{|l|}{$\mathrm{pH}$} \\
\hline Sham & $7.46 \pm 0.02$ & $7.43 \pm 0.02 *$ & $7.44 \pm 0.02 *$ & $7.45 \pm 0.02 *$ & $7.46 \pm 0.01$ & $7.46 \pm 0.02$ \\
\hline H-R control & $7.50 \pm 0.02$ & $6.88 \pm 0.03$ & $6.91 \pm 0.04$ & $7.24 \pm 0.04$ & $7.36 \pm 0.04$ & $7.41 \pm 0.03$ \\
\hline NAC-treated & $7.51 \pm 0.02$ & $6.90 \pm 0.02$ & $6.92 \pm 0.03$ & $7.22 \pm 0.03$ & $7.37 \pm 0.02$ & $7.39 \pm 0.01$ \\
\hline \multicolumn{7}{|l|}{$\mathrm{PaO}_{2}(\mathrm{mmHg})$} \\
\hline Sham & $67 \pm 4$ & $63 \pm 2 *$ & $64 \pm 2^{*}$ & $63 \pm 3^{*}$ & $64 \pm 3$ & $63 \pm 2$ \\
\hline H-R control & $68 \pm 4$ & $29 \pm 3$ & $421 \pm 19$ & $395 \pm 16$ & $67 \pm 2$ & $70 \pm 2$ \\
\hline NAC-treated & $66 \pm 3$ & $31 \pm 2$ & $407 \pm 32$ & $401 \pm 21$ & $76 \pm 8$ & $70 \pm 5$ \\
\hline \multicolumn{7}{|l|}{$\mathrm{PaCO}_{2}(\mathrm{mmHg})$} \\
\hline Sham & $36 \pm 1$ & $39 \pm 1$ & $37 \pm 1$ & $38 \pm 2$ & $35 \pm 1$ & $37 \pm 1$ \\
\hline H-R control & $33 \pm 2$ & $42 \pm 3$ & $38 \pm 2$ & $35 \pm 2$ & $34 \pm 2$ & $35 \pm 2$ \\
\hline NAC-treated & $37 \pm 1$ & $41 \pm 2$ & $41 \pm 1$ & $39 \pm 2$ & $36 \pm 1$ & $39 \pm 1$ \\
\hline \multicolumn{7}{|l|}{$\mathrm{HCO}_{3}(\mathrm{mmol} / \mathrm{L})$} \\
\hline Sham & $25 \pm 2$ & $26 \pm 1^{*}$ & $25 \pm 1^{*}$ & $26 \pm 1^{*}$ & $25 \pm 1 *$ & $26 \pm 1$ \\
\hline H-R control & $26 \pm 1$ & $8 \pm 1$ & $8 \pm 1$ & $15 \pm 1$ & $19 \pm 2$ & $22 \pm 2$ \\
\hline NAC-treated & $26 \pm 1$ & $8 \pm 1$ & $11 \pm 1$ & $15 \pm 1$ & $21 \pm 1$ & $23 \pm 1$ \\
\hline \multicolumn{7}{|c|}{ Heart Rate (beat/min) } \\
\hline Sham & $195 \pm 11$ & $190 \pm 18$ & $195 \pm 16$ & $205 \pm 18$ & $209 \pm 18$ & $208 \pm 13$ \\
\hline H-R control & $181 \pm 9$ & $214 \pm 11$ & $208 \pm 12$ & $209 \pm 13$ & $222 \pm 14$ & $218 \pm 13$ \\
\hline NAC-treated & $184 \pm 10$ & $204 \pm 8$ & $206 \pm 10$ & $215 \pm 7$ & $228 \pm 15$ & $214 \pm 8$ \\
\hline \multicolumn{7}{|c|}{ Mean arterial pressure (MAP) (mmHg) } \\
\hline Sham & $64 \pm 6$ & $53 \pm 3$ & $55 \pm 3$ & $51 \pm 4$ & $52 \pm 4$ & $52 \pm 5$ \\
\hline H-R control & $69 \pm 2$ & $38 \pm 7$ & $72 \pm 5$ & $45 \pm 3$ & $43 \pm 3$ & $39 \pm 2$ \\
\hline NAC-treated & $71 \pm 1$ & $36 \pm 5$ & $62 \pm 5$ & $44 \pm 2$ & $38 \pm 2$ & $38 \pm 3$ \\
\hline
\end{tabular}

$* p<0.05$ vs. H-R control.

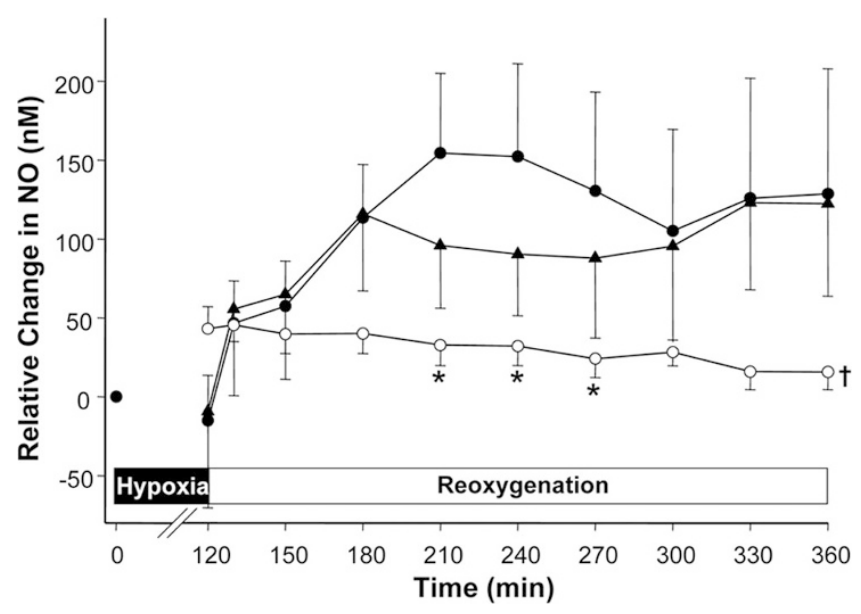

Figure 1. Temporal changes in cortical nitric oxide (NO) concentration in sham-operated piglets $(\mathrm{O}$, without hypoxia and reoxygenation $[\mathrm{H}-\mathrm{R}])$ and hypoxic piglets receiving either saline $(\bullet, \mathrm{H}-\mathrm{R}$ control) or NAC $(\mathbf{\Delta}) 5 \mathrm{~min}$ after reoxygenation and thereafter. $\dagger p<0.05 v s$. H-R control (two-way repeated measures ANOVA); ${ }^{*} p<0.05 v s$. H-R controls (one-way ANOVA).

NAC-treated groups tended to decrease during hypoxia (Fig. 2). After reoxygenation, the $\mathrm{H}_{2} \mathrm{O}_{2}$ concentration increased gradually toward the normoxic baseline within the first $2 \mathrm{~h}$. The increase in $\mathrm{H}_{2} \mathrm{O}_{2}$ concentration became significantly above normoxic baseline during the next $2 \mathrm{~h}$ of reoxygenation (Fig. 2). The maximum increase was $306 \pm 120 \mu \mathrm{M}$ noted at $4 \mathrm{~h}$ of reoxygenation in the H-R control group. The postresuscitation administration of NAC significantly attenuated the increased cortical $\mathrm{H}_{2} \mathrm{O}_{2}$ concentration during reoxygenation (Fig. 2).

Effects of NAC on CBF and oxygen delivery. There were significant changes in $\mathrm{CBF}$ and carotid vascular resistance of

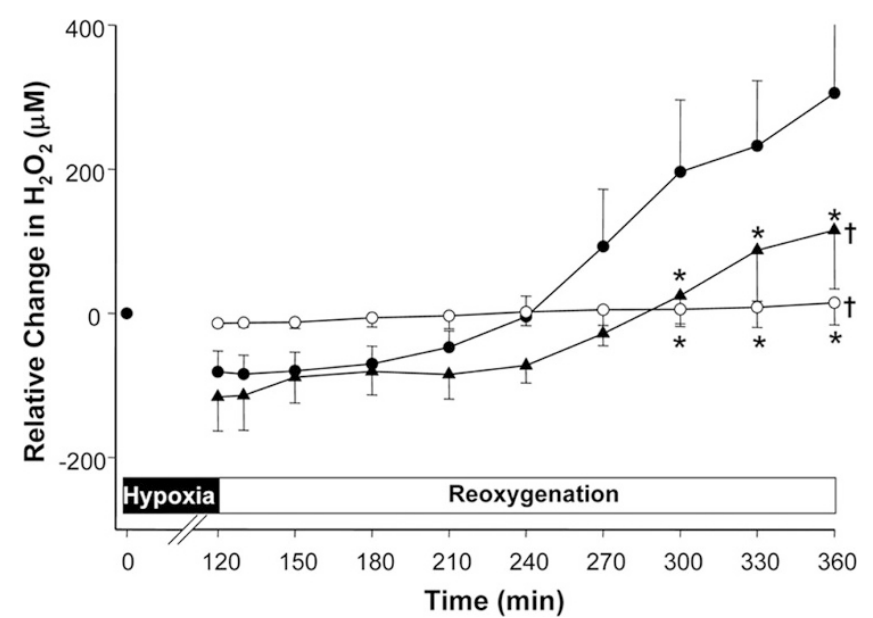

Figure 2. Temporal changes in cortical hydrogen peroxide $\left(\mathrm{H}_{2} \mathrm{O}_{2}\right)$ concentration in sham-operated piglets $(O$, without hypoxia and reoxygenation $[\mathrm{H}-\mathrm{R}])$ and hypoxic piglets receiving either saline $(\boldsymbol{O}, \mathrm{H}-\mathrm{R}$ control) or NAC (A) 5 minutes after reoxygenation and thereafter. $\dagger p<0.05$ vs. H-R control (two-way repeated measures ANOVA); $* p<0.05$ vs. H-R controls (one-way ANOVA).

the H-R control group during reoxygenation (versus shamoperated piglets) (Fig. 3). Upon reoxygenation, the CBF of $\mathrm{H}-\mathrm{R}$ control piglets decreased to $56 \%$ of normoxic baseline within $60 \mathrm{~min}$ and then remained low throughout the remaining period (Fig. 3A). The carotid vascular resistance increased immediately upon reoxygenation and remained high throughout the remaining period (Fig. 3B).

In piglets treated with $\mathrm{NAC}$ after reoxygenation, the $\mathrm{CBF}$ was significantly higher than that of the H-R control group and was not different from that of sham-operated piglets (Fig. 3A). Associated with the higher blood flow, the carotid vascular resistance 

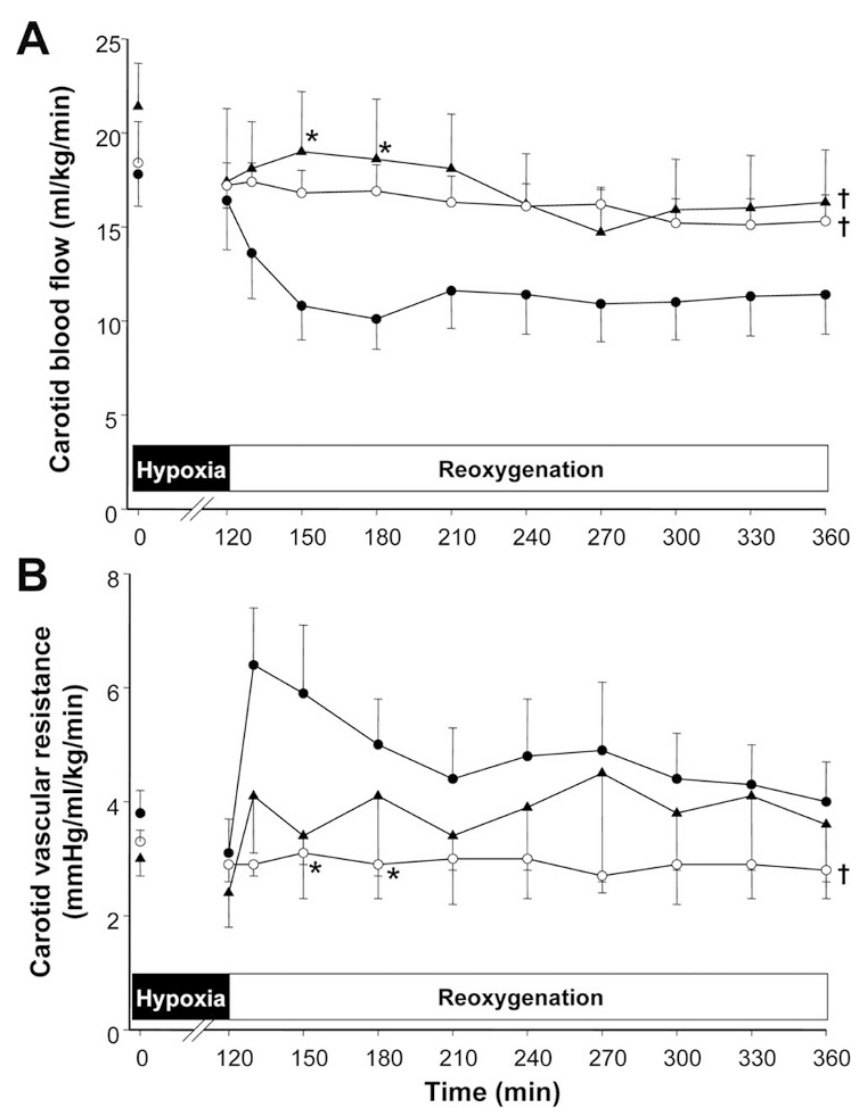

Figure 3. Temporal changes in $(A)$ carotid blood flow and $(B)$ carotid vascular resistance in sham-operated piglets $(\bigcirc$, without hypoxia and reoxygenation $[\mathrm{H}-\mathrm{R}])$ and hypoxic piglets receiving either saline $(\boldsymbol{O}, \mathrm{H}-\mathrm{R}$ control) or NAC $(\boldsymbol{\Delta}) 5$ minutes after reoxygenation and thereafter. $\dagger p<0.05 v s$. H-R control (two-way repeated measures ANOVA); $* p<0.05 v s$. H-R controls (one-way ANOVA).

of the NAC-treated animals tended to be lower than that of the H-R control group throughout the reoxygenation period (Fig. $3 B)$.

The changes in carotid oxygen delivery during H-R corresponded to those of CBF. At $2 \mathrm{~h}$ of hypoxia, the carotid oxygen delivery of $2 \mathrm{H}-\mathrm{R}$ groups decreased approximately $80 \%$ of the normoxic baseline with no significant difference between them. The carotid oxygen delivery of H-R controls returned to $78 \%$ of the normoxic baseline immediately upon reoxygenation with $100 \%$ oxygen. The carotid oxygen delivery recovered to the normoxic baseline in piglets treated with NAC and maintained higher than that of the H-R control group throughout the reoxygenation period $(p<0.05)$. The H-R control piglets had significantly higher cerebral cortical lactate levels than that of sham-operated piglets at the end of experiment (Fig. 4). Treating the animal with NAC significantly reduced the cortical lactate level.

Effects of NAC on cortical glutathione and nitrotyrosine levels. In the cerebral cortical tissue after H-R, there was a significant increase in GSSG level in the H-R control group (versus sham-operated piglets) (Table 2). The cortical GSSG level was significantly reduced in the NAC-treated piglets (versus $\mathrm{H}-\mathrm{R}$ controls) and was not different from that of the sham-operated group. Total GSH levels were not different among groups (Table 2). These changes in GSH and GSSG

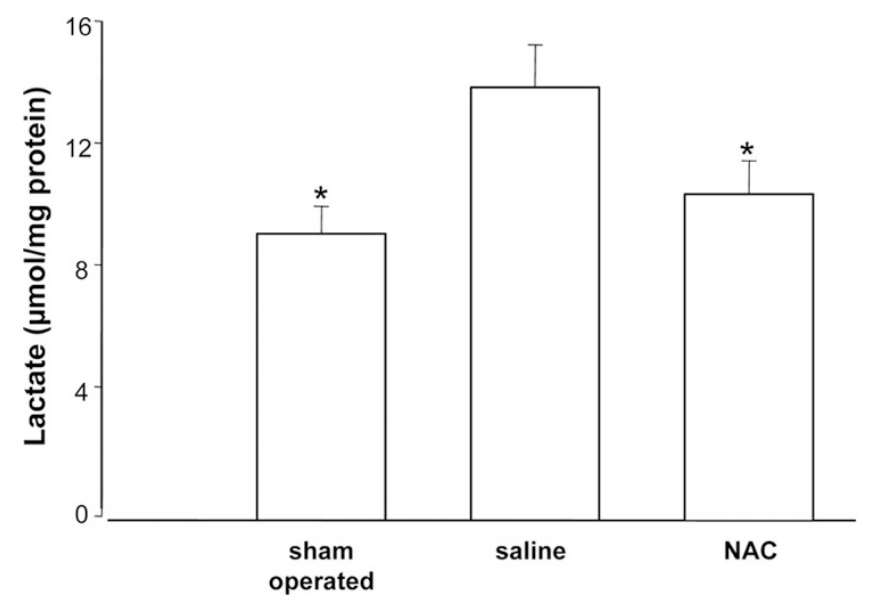

Figure 4. Cerebral cortical lactate levels of hypoxic piglets after $4 \mathrm{~h}$ of reoxygenation, which received either saline or NAC $5 \mathrm{~min}$ after reoxygenation. Sham-operated piglets had no hypoxia and reoxygenation. ${ }^{*} p<0.05$ vs. H-R controls (one-way ANOVA).

levels resulted in a slight increase in glutathione redox (GSSG:GSH) ratio (Table 2). The accumulated cortical $\mathrm{H}_{2} \mathrm{O}_{2}$, but not NO, significantly correlated with GSSG concentration $(r=0.6, p<0.01)$.

There was no difference in cerebral cortical nitrotyrosine levels among groups (Table 2). The cortical nitrotyrosine levels correlated positively with the cortical GSSG and lactate levels $(r=0.5, p<0.05$ and $r=0.6, p<0.01$, respectively). No significant correlation was found between the cortical nitrotyrosine levels and accumulated cortical $\mathrm{H}_{2} \mathrm{O}_{2}$ and $\mathrm{NO}$ concentrations.

\section{DISCUSSION}

Herein we report the effect of postresuscitation NAC on cortical $\mathrm{NO}$ and $\mathrm{H}_{2} \mathrm{O}_{2}$ production as well as cerebral perfusion in newborn piglets after H-R. Much controversy has arisen on whether NAC ameliorates oxidative stress by reducing NO production. Our results demonstrate that NAC reduces oxidative stress and improves cerebral oxygen delivery without affecting cerebral cortical NO production in reoxygenated newborn piglets after a severe hypoxic insult. To our knowledge, this is the first study to provide the real-time simultaneous measurements of $\mathrm{NO}$ and $\mathrm{H}_{2} \mathrm{O}_{2}$ during neonatal $\mathrm{H}-\mathrm{R}$.

Using specific electrochemical $\mathrm{NO}$ and $\mathrm{H}_{2} \mathrm{O}_{2}$ sensors $(4,14,15)$, we measured the cortical $\mathrm{NO}$ and $\mathrm{H}_{2} \mathrm{O}_{2}$ production during $\mathrm{H}-\mathrm{R}$ directly. Interestingly, two distinct patterns were observed with these two ROS during resuscitation. NO level increased immediately and reached its peak between 90-120 min after reoxygenation. Similar to our observation, a rapid rise in cortical NO concentration after resuscitation has been previously reported $(9,10)$. Kutzche et al. (9) reported a gradual decrease in NO concentration toward baseline value within $2 \mathrm{~h}$ of reoxygenation. We observed that the cortical $\mathrm{NO}$ level maintained above the baseline value throughout the reoxygenation period. The discrepancy could be because of the difference in hypoxia protocols as the cortical NO level has also been shown to maintain steadily high throughout the reperfusion period in adult piglets after cardiopulmonary by- 
Table 2. Effects of NAC on cerebral cortical glutathione and nitrotyrosine levels after hypoxic-reoxygenation

\begin{tabular}{lcccc}
\hline & Sham & H-R control & NAC-treated & \\
\hline Glutathione & & & & \\
GSH (nmol/mg protein) & $29.9 \pm 1.3$ & $32.6 \pm 1.4$ & $25.6 \pm 3.6$ & 0.152 \\
GSSG (nmol/mg protein) & $4.1 \pm 0.5^{*}$ & $6.2 \pm 0.9$ & $3.0 \pm 0.2^{*}$ & 0.006 \\
GSSG:GSH ratio & $0.13 \pm 0.01$ & $0.20 \pm 0.03$ & $0.13 \pm 0.02$ & 0.103 \\
Nitrotyrosine (pmol/mg protein) & $0.67 \pm 0.02$ & $0.92 \pm 0.17$ & $0.67 \pm 0.06$ & 0.216 \\
\hline
\end{tabular}

$* p<0.05$ vs. H-R control.

pass (10). Alternatively, the different observations in postresuscitation changes in cortical NO could be because of the placement of the electrochemical sensor. As compared with the cerebral cortex, higher NO concentration was noted in the caudate nucleus under similar experimental settings during reoxygenation (9). Because our sensor was placed deeper than that of the previous study (6 versus $2-3 \mathrm{~mm}$, respectively), it could account for different observations during reoxygenation.

In contrast to the immediate upsurge of cortical NO, the cortical $\mathrm{H}_{2} \mathrm{O}_{2}$ level of H-R control animals increased gradually at the early period of reoxygenation and then elevated markedly at the later stage. As the result of an endogenous defense system, $\mathrm{H}_{2} \mathrm{O}_{2}$ production depends on the interaction between superoxide anion and NO (forming peroxynitrite) (16), and superoxide dismutase (17). An increase in superoxide release has been observed after inhibiting NO formation in perfused rat's liver (18). Further, it has been shown recently that reducing $\mathrm{NO}$ could lead to enhanced formation of $\mathrm{H}_{2} \mathrm{O}_{2}$ (19). Therefore, the overproduction of NO in early reoxygenation may limit the bioavailability of superoxide with subsequent decreased $\mathrm{H}_{2} \mathrm{O}_{2}$ production at this stage. This notion is supported by the observation that $\mathrm{H}_{2} \mathrm{O}_{2}$ level only increased markedly after NO reached its peak. However, the gradual increase in $\mathrm{H}_{2} \mathrm{O}_{2}$ observed in the present study could also be secondary to the gradual accumulation of $\mathrm{H}_{2} \mathrm{O}_{2}$ as well as from the loss of efficacy of endogenous scavenging systems.

NAC can affect the bioavailability of NO through inhibiting inducible NO synthase activity in vitro (20) and in vivo (21), and/or forming more active NO adducts $(22,23)$. Thus, contradictory observations have been reported on the effects of NAC on NO production during I-R and H-R. Associated with reducing brain injury, NAC has been shown to decrease plasma nitrate-nitrite levels in I-R gerbils (6) as well as NO synthase expression in I-R rats (2). In contrast, an increase in nitrate-nitrite levels in I-R renal tissue (7) and plasma of I-R limb injury (8) has been reported after NAC treatment. Although the cortical NO concentration was not affected by NAC treatment, the physiologic significance of the increased NO concentration during reoxygenation remains to be determined. Based on our findings, we speculate that NAC exerts its beneficial effects either directly by scavenging ROS or indirectly by enhancing the endogenous glutathione system, resulting in an improved oxidative state, as reported previously (11), instead of through mechanisms related to NO production during H-R.

Despite the lack of significant difference, the cortical nitrotyrosine levels correlated positively with the concentrations of GSSG and lactate, indicating that change in nitrotyrosine level in the present study may represent the state of oxidative stress in the brain of these severely hypoxic animals. Nitrotyrosine formation has been commonly used as an indicator of peroxynitrite. The reaction of $\mathrm{H}_{2} \mathrm{O}_{2}$ and myeloperoxidase can also lead to the formation of nitrotyrosine (24). Therefore, NAC can reduce the accumulation of nitrotyrosine by either directly scavenging peroxynitrite $(25,26)$ or indirectly reducing the bioavailability of $\mathrm{H}_{2} \mathrm{O}_{2}$ for nitrotyrosine formation. Similar to our finding, a significant reduction of tissue lipid peroxidation after acute NAC administration has also been reported previously $(4,27)$. Minimizing the lipid peroxidation with NAC may provide beneficial effects after an H-R insult.

It is generally believed that abnormal cerebral blood flow during and after hypoxia contributes to H-R tissue injury. As it has been demonstrated that initial hyperemia after hypoxia or ischemia represents a prerequisite to neuronal functional recovery (28), any treatment that improves cerebral blood flow after hypoxia should have a protective effect. To investigate whether NAC can elicit its beneficial effect by maintaining the proper cerebral circulation during reoxygenation, the cerebral blood flow was evaluated indirectly by measuring the CBF in the present study. Although CBF also supplies extracranial tissues, a direct correlation between CBF and cerebral blood flow has been demonstrated previously in animal models of H-R (12) and I-R (29). In the present study, decreased CBF with vasoconstriction was observed in the H-R control animals, resulting in lower oxygen delivery and higher brain lactate levels upon reoxygenation. Increased endogenous NO bioavailability has been demonstrated to maintain cerebral blood flow after I-R (30) and H-R (31). These results seem contradictory to our observation that an upsurge of $\mathrm{NO}$ is associated with a decrease in CBF throughout the reoxygenation period. The discrepancy between cerebral microcirculation and cortical NO concentration has also been reported earlier in H-R piglets (9). However, in addition to the limitation of these surrogate measures of cerebral perfusion, caution must be exercised in correlating vascular effect with cortical NO level, which does not reflect the NO level from endothelial origin.

It has been demonstrated that hyperoxia causes vasoconstriction by enhancing superoxide generation and decreasing basal vasodilating effects of $\mathrm{NO}$ (32), and increasing production of potent vasoconstrictive agents including peroxynitrite, matrix metalloproteinase-2, and endothelin $(33,34)$. Interestingly, we observed a dose-response effect of graded reoxygenation on the carotid hemodynamics in asphyxiated newborn piglets and the associated increased tissue matrix metalloproteinase-2 activity in the brain (12). Therefore, interventions to reduce ROS production may protect against oxidative stress-induced vasoconstriction, as supported by the 
findings with NAC treatment. In contrast to the vasoconstriction observed in the control animals, the carotid vascular resistance of the animal receiving NAC was similar to the sham-operated group after reoxygenation. Furthermore, NAC improved renal blood flow in asphyxiated piglets (11) and ischemic rats (25). The vasomodulatory mechanisms of NAC may include its antioxidant/peroxynitrite-scavenging properties (25) and improving endothelial dysfunction $(22,23)$.

In summary, we here reported the real-time changes in both cortical $\mathrm{H}_{2} \mathrm{O}_{2}$ and $\mathrm{NO}$ activities during $\mathrm{H}-\mathrm{R}$ in newborn piglets. Treating the animal with NAC minimizes oxidative stress by suppressing the $\mathrm{H}_{2} \mathrm{O}_{2}$, but not NO production. Functionally, NAC also improves cerebral blood flow and reduces brain lactate accumulation. However, the experimental course is short and no histologic and functional outcome was studied. Further research is warranted to confirm whether the postresuscitation administration of NAC provides neuroprotection against oxidative stressrelated injury to asphyxiated neonates.

\section{REFERENCES}

1. Rodrigo J, Fernandez AP, Serrano J, Peinado MA, Martinez A 2005 The role of free radicals in cerebral hypoxia and ischemia. Free Radic Biol Med 39:26-50

2. Khan M, Sekhon B, Jatana M, Giri S, Gilg AG, Sekhon C, Singh I, Singh AK 2004 Administration of $\mathrm{N}$-acetylcysteine after focal cerebral ischemia protects brain and reduces inflammation in rat model of experimental stroke. J Neurosci Res 76:519527

3. Wang X, Svedin P, Nie C, Lapatto R, Zhu C, Gustavsson M, Sandberg M, Karlsson JO, Romero R, Hagberg H, Mallard C 2007 N-Acetylcysteine reduces lipopolysaccharide-sensitized hypoxic-ischemic brain injury. Ann Neurol 61:263-271

4. Lee TF, Jantzie LL, Todd KG, Cheung PY 2008 Post-resuscitation N-acetylcysteine treatment reduces cerebral hydrogen peroxide in the hypoxic piglet brain. Intensive Care Med 34:190-197

5. Matsui T, Nagafuji T, Kumanishi T, Asano T 1999 Role of nitric oxide in pathogenesis underlying ischemic cerebral damage. Cell Mol Neurobiol 19:177-189

6. Cuzzocrea S, Mazzon E, Costantino G, Serraino I, Dugo L, Calabro G, Cucinotta G, De Sarro A, Caputi AP 2000 Beneficial effects of $\mathrm{N}$-acetylcysteine on ischemic brain injury. Br J Pharmacol 130:1219-1226

7. Salom MG, Arregui B, Carbonell LF, Ruiz F, Gonzalez-Mora JL, Fenoy FJ 2005 Renal ischemia induces an increase in nitric oxide levels from tissue stores. Am J Physiol Regul Integr Comp Physiol 289:R1459-R1466

8. Bolcal C, Yildirim V, Doganci S, Sargin M, Aydin A, Eken A, Ozal E, Kuralay E, Demirkilic U, Tatar H 2007 Protective effects of antioxidant medications on limb ischemia reperfusion injury. J Surg Res 139:274-279

9. Kutzsche S, Kirkeby OJ, Rise IR, Saugstad OD 1999 Effects of hypoxia and reoxygenation with $21 \%$ and $100 \%$-oxygen on cerebral nitric oxide concentration and microcirculation in newborn piglets. Biol Neonate 76:153-167

10. Segawa D, Hatori N, Yoshizu H, Uriuda Y, Shimizu M, Tanaka S 1998 The effect of nitric oxide synthase inhibitor on reperfusion injury of the brain under hypothermic circulatory arrest. J Thorac Cardiovasc Surg 115:925-930

11. Johnson ST, Bigam DL, Emara M, Obaid L, Slack G, Korbutt G, Jewell LD, Van Aerde J, Cheung PY $2007 \mathrm{~N}$-acetylcysteine improves the hemodynamics and oxidative stress in hypoxic newborn pigs reoxygenated with $100 \%$ oxygen. Shock 28:484-490
12. Richards JG, Todd KG, Emara M, Haase E, Cooper SL, Bigam DL, Cheung PY 2006 A dose-response study of graded reoxygenation on the carotid haemodynamics, matrix metalloproteinase-2 activities and amino acid concentrations in the brain of asphyxiated newborn piglets. Resuscitation 69:319-327

13. Martin LJ, Brambrink A, Koehler RC, Traystman RJ 1997 Primary sensory and forebrain motor systems in the newborn brain are preferentially damaged by hypoxia-ischemia. J Comp Neurol 377:262-285

14. Kulagina NV, Michael AC 2003 Monitoring hydrogen peroxide in the extracellular space of the brain with amperometric microsensors. Anal Chem 75:4875-4881

15. Zhang X, Cardosa L, Broderick M, Fein H, Lin J 2000 An integrated nitric oxide sensor based on carbon fiber coated with selective membranes. Electroanalysis 12:1113-1117

16. Beckman JS, Ischiropoulos H, Zhu L, van der Woerd M, Smith C, Chen J, Harrison J, Martin JC, Tsai M 1992 Kinetics of superoxide dismutase-and iron-catalyzed nitration of phenolics by peroxynitrite. Arch Biochem Biophys 298:438-445

17. Cai H 2005 Hydrogen peroxide regulation of endothelial function: origins, mechanisms, and consequences. Cardiovasc Res 68:26-36

18. Bautista AP, Spitzer JJ 1994 Inhibition of nitric oxide formation in vivo enhances superoxide release by the perfused liver. Am J Physiol 266:G783-G788

19. Thomas DD, Ridnour LA, Espey MG, Donzelli S, Ambs S, Hussain SP, Harris CC, DeGraff W, Roberts DD, Mitchell JB, Wink DA 2006 Superoxide fluxes limit nitric oxide-induced signaling. J Biol Chem 281:25984-25993

20. Pahan K, Sheikh FG, Namboodiri AM, Singh I 1998 N-acetylcysteine inhibits induction of NO production by endotoxin or cytokine stimulated rat peritoneal macrophages, C6 glial cells and astrocytes. Free Radic Biol Med 24:39-48

21. Bergamini S, Rota C, Canali R, Staffieri M, Daneri F, Bini A, Giovannini F, Tomasi A, Iannone A $2001 \mathrm{~N}$-acetylcysteine inhibits in vivo nitric oxide production by inducible nitric oxide synthase. Nitric Oxide 5:349-360

22. Andrews NP, Prasad A, Quyyumi AA $2001 \mathrm{~N}$-acetylcysteine improves coronary and peripheral vascular function. J Am Coll Cardiol 37:117-123

23. Scharfstein JS, Keaney JF Jr, Slivka A, Welch GN, Vita JA, Stamler JS, Loscalzo J 1994 In vivo transfer of nitric oxide between a plasma protein-bound reservoir and low molecular weight thiols. J Clin Invest 94:1432-1439

24. Eiserich JP, Hristova M, Cross CE, Jones AD, Freeman BA, Halliwell B, van der Vliet A 1998 Formation of nitric oxide-derived inflammatory oxidants by myeloperoxidase in neutrophils. Nature 391:393-397

25. Conesa EL, Valero F, Nadal JC, Fenoy FJ, Lopez B, Arregui B, Salom MG 2001 $\mathrm{N}$-acetyl-L-cysteine improves renal medullary hypoperfusion in acute renal failure. Am J Physiol Regul Integr Comp Physiol 281:R730-R737

26. Carbonell LF, Diaz J, Hernandez I, Cuevas S, Valero F, Quesada T, Fenoy F, Salom MG $2007 \mathrm{~N}$-acetylcysteine exerts protective effects and prevents lung redox imbalance and peroxynitrite generation in endotoxemic rats. Med Chem 3:29-34

27. Caglikulekci M, Dirlik M, Pata C, Plasse M, Tamer L, Ogetman Z, Ercan B 2006 Effect of $\mathrm{N}$-acetylcysteine on blood and tissue lipid peroxidation in lipopolysaccharide-induced obstructive jaundice. J Invest Surg 19:175-184

28. Cerchiari EL, Hoet TM, Safar P, Sclabassi RJ 1987 Protective effects of combined superoxide dismutase and deferoxamine on recovery of cerebral blood flow and function after cardiac arrest in dogs. Stroke 18:869-878

29. Gratton R, Carmichael L, Homan J, Richardson B 1996 Carotid arterial blood flow in the bovine fetus as a continuous measure of cerebral blood flow. J Soc Gynecol Investig 3:60-65

30. Willmot MR, Bath PM 2003 The potential of nitric oxide therapeutics in stroke. Expert Opin Investig Drugs 12:455-470

31. Uetsuka S, Fujisawa H, Yasuda H, Shima H, Suzuki M 2002 Severe cerebral blood flow reduction inhibits nitric oxide synthesis. J Neurotrauma 19:1105-1116

32. Demchenko IT, Oury TD, Crapo JD, Piantadosi CA 2002 Regulation of brain's vascular responses to oxygen. Circ Res 91:1031-1037

33. Davidge ST 1998 Oxidative stress and altered endothelial cell function in preeclampsia. Semin Reprod Endocrinol 16:65-73

34. Belik J, Jankov RP, Pan J, Tanswell AK 2004 Peroxynitrite inhibits relaxation and induces pulmonary artery muscle contraction in the newborn rat. Free Radic Biol Med 37:1384-1392 